\title{
High prevalence of potentially virulent strains of Helicobacter pylori in the general male British population
}

\author{
J Danesh, P Whincup, M Walker, L Lennon, A Thomson, P Appleby, C Hawkey, \\ J C Atherton
}

Clinical Trial Service Unit and

Epidemiological

Studies Unit,

University of Oxford,

Radcliffe Infirmary,

Oxford OX2 6HE, UK

J Danesh

Department of Public Health Sciences, St

George's Hospital

Medical School,

London SW17 0RE, UK

P Whincup

Department of

Primary Care and

Population Sciences,

Royal Free UCL

Medical School,

London, UK

$M$ Walker

L Lennon

A Thomson

ICRF Cancer

Epidemiology Unit,

Oxford, UK

P Appleby

Division of

Gastroenterology and

Institute of Infections

and Immunity,

University of

Nottingham, UK

C Hawkey

J C Atherton

Correspondence to:

Dr J Danesh

Accepted for publication 8 February 2000

\begin{abstract}
Background-Strains of Helicobacter pylori that express the cytotoxin associated gene product A (CagA) may be more strongly associated with serious gastric diseases, such as gastric cancer and peptic ulceration, than other strains. Data, however, are sparse on the prevalence, risk factors, and other correlates of these strains in the general population.

Aim-To characterise aspects of the seroepidemiology of $\mathrm{CagA}^{+}$strains of $\mathrm{H}$ pylori in the general British population.

Methods-We measured serum IgG antibodies to mixed $H$ pylori antigens and separately to CagA in 1025 men aged 40-59 years who were randomly selected from a larger group of participants in a community based survey conducted in 18 different British towns.

Results-Overall, 44\% (95\% confidence interval $41-47 \%$ ) of the men were seropositive to CagA antibodies, representing about $61 \%(57-65 \%)$ of the men seropositive to mixed antigen $H$ pylori. The risk factors for seropositivity to CagA antibodies were similar to those for seropositivity to mixed antigen $H$ pylori, apart from an increased prevalence of reported bedroom sharing in childhood $(\mathbf{p}<0.01)$.

Conclusion-In a nationwide study of potentially virulent $H$ pylori strains, there was a high prevalence of the infection, with some evidence that acquisition of such strains might occur earlier in life than other strains.

(Gut 2000;47:23-25)
\end{abstract}

Keywords: Helicobacter pylori; cytotoxin associated gene A

Despite suggestions that potentially virulent strains of Helicobacter pylori infection produce greater risks of gastric inflammation, peptic ulceration, and gastric cancer than other strains, little is known about the characteristics of these organisms in the general population, such as their prevalence, geographical variation, risk factors, and any relationship with markers of systemic inflammation..$^{1-8}$ Here we report a nationwide investigation of cytotoxin associated gene product $\mathrm{A}\left(\mathrm{cagA}^{+}\right)$ strains of $H$ pylori in 1025 middle aged British men.

\section{Methods}

During 1978-1980, 7735 males, aged 40-59 years (response rate $78 \%$ ), were randomly selected from general practice registers in 24 British towns where nurses administered questionnaires and performed physical measurements. In 5661 men from 18 of the towns, non-fasting venous blood samples were collected and stored at $-20^{\circ} \mathrm{C}$ for subsequent analysis. ${ }^{9}$ Additional questionnaires on car ownership and childhood social circumstances were posted at five years $(98 \%$ response among survivors) and at 12 years after entry (90\% response among survivors), respectively. Among the 5016 men who remained free of incident coronary heart disease by 1996, 1025 were randomly selected for measurements of Helicobacter pylori specific IgG titres using an ELISA kit (Premier, Meridian Diagnostics, Cincinnati, Ohio, USA) and anti-CagA serum antibodies using recombinant CagA antigen orv220. ${ }^{2}$ Our CagA assay had $92 \%$ (34/37) sensitivity and $96 \%(24 / 25)$ specificity in 62 patients in another study in whom CagA status was directly assessed by western blot in gastric biopsy specimens (Helicoblot, 2.0, Genelabs Diagnostics, Singapore). This level of accuracy is comparable with that described for the original serological assay ${ }^{2}$ and is confirmed by the fact that only two individuals seronegative to mixed antigen $H$ pylori in the present study tested CagA seropositive.

\section{Results}

A total of 448 ( $44 \%$ (95\% confidence interval $41-47 \%)$ ) of the 1025 men were seropositive to CagA antibodies, representing about $61 \%$ (57-65\%) of the men seropositive to mixed antigen $H$ pylori (table 1). Seropositivity to CagA antibodies was more common in men

Abbreviations used in this paper: $\mathrm{CagA}$, cytotoxin associated gene product $\mathrm{A}$. 
Table 1 Levels of risk factors and other characteristics by Helicobacter pylori seropositivity and CagA serostatus in 1025 British men aged 40-59 years (mean (SD) or number (\%))

\begin{tabular}{|c|c|c|c|c|}
\hline & \multirow{2}{*}{$\begin{array}{l}\text { H pylori } \\
\text { seronegative } \\
(n=285)\end{array}$} & \multicolumn{3}{|l|}{ H pylori seropositive } \\
\hline & & All $\mathrm{Hp}+(n=740)$ & $\operatorname{Cag} A-(n=292)$ & $\operatorname{Cag} A+(n=448)$ \\
\hline Age $(y)$ & $51(3)$ & $53(4)^{\star}$ & $52(5)$ & $53(5)$ \\
\hline Current smoker & $93(33 \%)$ & $343(46 \%)$ & $135(46 \%)$ & $208(46 \%)$ \\
\hline$>2$ drinks alcohol/day & $58(20 \%)$ & $173(23 \%)$ & $75(26 \%)$ & $98(22 \%)$ \\
\hline \multicolumn{5}{|l|}{ Adult socioeconomic factors } \\
\hline Occupation in social class I or II & $121(42 \%)$ & $158(21 \%)^{\star \star \star \star \star}$ & $66(23 \%)$ & $92(21 \%)$ \\
\hline Homeowner & $230(83 \%)$ & $437(64 \%)^{\star \star}$ & $178(66 \%)$ & $129(62 \%)$ \\
\hline Married & $252(82 \%)$ & $652(88 \%)$ & $251(86 \%)$ & $401(90 \%)$ \\
\hline Car owner & $246(89 \%)$ & $493(72 \%)^{\star \star}$ & $202(75 \%)$ & $291(70 \%)$ \\
\hline \multicolumn{5}{|l|}{ Childhood socioeconomic factors } \\
\hline Father with non-manual job & $78(32 \%)$ & $113(21 \%)$ & $49(23 \%)$ & $64(20 \%)$ \\
\hline Family owned a car & $52(21 \%)$ & $64(11 \%)$ & $28(13 \%)$ & $36(10 \%)$ \\
\hline Bathroom in house & $146(58 \%)$ & $253(44 \%)^{\star}$ & $110(49 \%)$ & $143(42 \%)$ \\
\hline Hot water tap in house & $137(55 \%)$ & $274(48 \%)$ & $116(52 \%)$ & $158(46 \%)$ \\
\hline Bedroom shared & $124(49 \%)$ & $409(72 \%)^{\star \star \star}$ & $148(66 \%)$ & $261(76 \%)^{\star}$ \\
\hline \multicolumn{5}{|l|}{ Physical measurements } \\
\hline Body mass index $\left(\mathrm{kg} / \mathrm{m}^{2}\right)$ & $25.3(1.7)$ & $25.4(2.6)$ & $25.3(3.3)$ & $25.4(3.5)$ \\
\hline Systolic blood pressure $(\mathrm{mm} \mathrm{Hg})$ & $144(12)$ & $147(16)$ & $148(21)$ & $147(21)$ \\
\hline Diastolic blood pressure (mm Hg) & $82(8)$ & $83(10)$ & $82(13)$ & $84(13)$ \\
\hline \multicolumn{5}{|l|}{ Blood markers of infection or inflammation } \\
\hline Chlamydia pneumoniae titres $\left(\mathrm{FC} \times 10^{6}\right)$ & $163(40)$ & $188(43)^{\star \star \star \star}$ & $186(57)$ & $189(58)$ \\
\hline $\log _{10}$ C-reactive protein $(\mathrm{mg} / \mathrm{l})$ & $0.05(0.31)$ & $0.19(0.38)$ & $0.19(0.51)$ & $0.19(0.55)$ \\
\hline $\log _{10}$ serum amyloid A protein $(\mathrm{mg} / \mathrm{l})$ & $0.83(0.16)$ & $0.84(0.24)$ & $0.83(0.31)$ & $0.85(0.31)$ \\
\hline Albumin $(\mathrm{g} / \mathrm{l})$ & $45.1(1.4)$ & $44.3(1.8)$ & $44.3(2.4)$ & $44.3(2.3)$ \\
\hline White cell count $\left(\times 10^{9} / 1\right)$ & $6.9(1.1)$ & $7.3(1.3)$ & $7.2(1.5)$ & $7.3(1.8)$ \\
\hline
\end{tabular}

The comparisons in the table involve columns $1 v 2$ (all H pylori seronegative $v$ all H pylori seropositive) and columns $3 v 4$ (among those $H$ pylori seropositive: CagA seronegatives $v$ CagA seropositives). Information on some factors was available in only a subset of participants. Car ownership: 964; father's occupation: 783; family car: 818; bathroom in house: 820; hot water supply: 818; bed sharing: 819. FC, fluorescent count.

$\mathrm{p}$ values are shown only after adjustment for age, cigarette smoking status, and indicators of socioeconomic status and are denoted by: ${ }^{\star} \mathrm{p}<0.01,{ }^{\star \star} \mathrm{p}<0.001,{ }^{\star \star \star} \mathrm{p}<0.0001,{ }^{\star \star \star \star}{ }^{*} \mathrm{p}<0.00001$. Adjustments for social class were omitted in the regressions involving markers of socioeconomic status. Emphasis was given to results more extreme than 2.6 standard deviations ( $\mathrm{p} \approx 0.01$ ) to make some allowance for multiple comparisons.

resident in northern England and Scotland than in southern England ( $49 \%$ v 28\%, p $<0.00001$ ), with a similar geographical pattern for seropositivity to mixed antigen $H$ pylori $(79 \%$ v 53\%; $\mathrm{p}<0.00001)$. Reported bedroom sharing in childhood was more frequent in CagA seropositive men compared with $H$ pylori infected CagA seronegative men $(76 \% v 66 \% ; \mathrm{p}<0.01)$. The strong correlation between $H$ pylori seropositivity and Chlamydia pneumoniae IgG titres $(\mathrm{p}<0.0001)$ did not change much after adjustment for age, cigarette smoking, and markers of socioeconomic status (suggesting that these two infective agents may share as yet unrecognised risk factors). ${ }^{10}$ Associations between $H$ pylori seropositivity and low $\mathrm{FEV}_{1}$ and short stature, however, weakened substantially after adjustments. The data were too sparse to subdivide reliably by town of residence and racial origin (the large majority of men were Caucasian).

\section{Discussion}

Previous studies have reported great variation in the prevalence of potentially virulent $H$ pylori strains with much higher prevalences generally reported in developing countries than in North America and western Europe. ${ }^{41112}$ Most, however, have been small studies conducted in selected populations or in selected regions within certain countries. By contrast, we conducted a nationwide community based study of cagA $^{+} H$ pylori strains, including detailed information on a number of possible risk factors and other characteristics in more than 1000 individuals. We found that about $45 \%$ of middle aged British men resident in 18 different towns in 1980 were infected with potentially more virulent strains of $H$ pylori. Moreover, we found a greater prevalence of these organisms in the less affluent regions of Scotland and northern England than in southern England. It may be that some of the individuals seropositive for CagA antibodies in this study were also coinfected with other $H$ pylori strains, but this would not alter the interpretation of the present findings.

As $H$ pylori is believed to be transmitted mainly by person-to-person contact, our observation that men infected with CagA positive strains of $H$ pylori reported bedroom sharing during childhood more frequently than men infected with other strains is consistent with suggestions that potentially virulent strains may be acquired earlier in life than other strains. ${ }^{13}$ More direct evidence is needed, however, to determine reliably both the timing and mode of transmission of various strains of the infection. We observed no strong associations between CagA seropositivity and blood markers of systemic inflammation, despite previous suggestions of increased intragastric inflammation in CagA positive individuals. ${ }^{3}$ We also observed no important differences between men infected and those not infected with CagA positive strains for a number of other characteristics listed in table 1, suggesting that these characteristics cannot explain differences in the strengths of association reported between different $H$ pylori subtypes and gastric diseases.

The recombinant CagA antigen used in this study was a gift of Orovax Inc, Cambridge, Massachusetts, USA. M Thomas, Y-K Wong, and $\mathrm{M}$ Ward provided Chlamydia pneumoniae serology and J R Gallimore and M B Pepys provided C-reactive protein
and serum amyloid A protein assays. J John provided valuable and serum amyloid A protein assays. J John provided valuable assistance. Professor G A Shaper established the British
Regional Heart Study, which is a British Heart Foundation Regional Heart Study, which is a British Heart Foundation
Research Group and also receives support from the Department Research Group and also receives support from the Department
of Health. JD is supported by a Merton College fellowship and of Health. JD is supported by a Merton College fellowship and
a Frohlich award. JA is supported by a Medical Research Council Clinician Scientist Fellowship. 
1 Blaser MJ. Not all Helicobacter pylori strains are created equal: should all be eliminated? Lancet 1997;349: equal:

2 Blaser MJ, Perez-Perez GI, Kleanthous H. Infection with Helicobacter pylori strains possessing cagA is associated with an increased risk of developing adenocarcinoma of the stomach. Cancer Res 1995;55:2111-15.

Atherton JC. H pylori virulence factors. Br Med Bull 1998; 54:105-20.

4 Parsonnet J, Friedman GD, Orentreich N, Vogelman H Risk factor for gastric cancer in people with CagA positive or CagA negative Helicobacter pylori infection. Gut 1997; 40:297-301.

5 Garner JA, Cover TL. Analysis of genetic diversity in cytotoxin-producing and non-cytotoxin-producing Helicobacter pylori strains. F Infect Dis 1995;172:290-3.

6 Parsonnet J, Replogle M, Yang S, Hiatt R. Seroprevalence of CagA-positive strains among Helicobacter pylori-infected, healthy young adults. F Infect Dis 1997;175:1240-2.

7 Atherton JC, Tham KT, Peek-RM J, Cover TL, Blaser MJ. Density of Helicobacter pylori infection in vivo as assessed by quantitative culture and histology. F Infect Dis 1996;174 $552-6$
8 Weel JF, van-der-Hulst RW, Gerrits Y, et al. The interrelationship between cytotoxin-associated gene A, vacuolating tionship between cytotoxin-associated gene A, vacuolating
cytotoxin, and Helicobacter pylori-related diseases. $\mathcal{F}$ Infect Dis 1996;173:1171-5.

9 Shaper AG, Pocock SJ, Walker M, Cohen NM, Wale CJ, Thomson AG. British Regional Heart Study: cardiovascular risk factors in middle-aged men in 24 towns. BMF 1981;283:179-86.

10 Danesh J, Wong Y-K, Ward M, Hawting P, Murphy M, Muir J. Strong correlation between Helicobacter pylori seropositivity and Chlamydia pneumoniae IgG titres. $\mathcal{F}$ Epidemiol Community Health 1998;52:821-2.

11 Torres J, Perez-Perez GI, Leal HY, Munoz O. Infection with CagA+ Helicobacter pylori strains as a possible predictor of risk in the development of gastric adenocarcinoma in Mexico. Int f Cancer 1998;78:298-300.

12 Webb PM, Crabtree JE, Forman D. Gastric cancer, cytotoxin-associated gene A-positive Helicobacter pylori, cyer Blaser MJ, Chyou PH, Nomura A. Age at establishment of Helicobacter pylori infection and gastric carcinoma, gastric Helicobacter pylori infection and gastric carcinoma, gastric
ulcer and duodenal ulcer risk. Cancer Res 1995;55:562-5. 